\title{
Using self-reported data on the social determinants of health in primary care to identify cancer screening disparities: opportunities and challenges
}

\author{
A.K. Lofters ${ }^{1,2,3,4,7^{*}}$ (D, A. Schuler ${ }^{1,3}$, M. Slater ${ }^{1}$, N.N. Baxter ${ }^{4,5}$, N. Persaud ${ }^{1,2,3}$, A.D. Pinto ${ }^{1,2,3,4}$, E. Kucharski ${ }^{6}$, S. Davie ${ }^{1}$, \\ R. Nisenbaum ${ }^{3,4}$ and T. Kiran ${ }^{1,2,3,7}$
}

\begin{abstract}
Background: Data on the social determinants of health can help primary care practices target improvement efforts, yet relevant data are rarely available. Our family practice located in Toronto, Ontario routinely collects patient-level sociodemographic data via a pilot-tested survey developed by a multi-organizational steering committee. We sought to use these data to assess the relationship between the social determinants and colorectal, cervical and breast cancer screening, and to describe the opportunities and challenges of using data on social determinants from a self-administered patient survey.

Methods: Patients of the family practice eligible for at least one of the three cancer screening types, based on age and screening guidelines as of June 30, 2015 and who had answered at least one question on a socio-demographic survey were included in the study. We linked self-reported data from the sociodemographic survey conducted in the waiting room with patients' electronic medical record data and cancer screening records. We created an individual-level income variable (low-income cut-off) that defined a poverty threshold and took household size into account. The sociodemographic characteristics of patients who were overdue for screening were compared to those who were up-to-date for screening for each cancer type using chi-squared tests.

Results: We analysed data for 5766 patients for whom we had survey data. Survey participants had significantly higher screening rates $(72.9,78.7,74.4 \%$ for colorectal, cervical and breast cancer screening respectively) than the 13, 036 patients for whom we did not have survey data $(59.2,65.3,58.9 \%$ respectively). Foreign-born patients were significantly more likely to be up-to-date on colorectal screening than their Canadian-born peers but showed no significant differences in breast or cervical cancer screening. We found a significant association between the low-income cut-off variable and cancer screening; neighbourhood income quintile was not significantly associated with cancer screening. Housing status was also significantly associated with colorectal, cervical and breast cancer screening. There was a large amount of missing data for the low-income cut-off variable, approximately 25\% across the three cohorts.
\end{abstract}

Conclusion: While we were able to show that neighbourhood income might under-estimate income-related disparities in screening, individual-level income was also the most challenging variable to collect. Future work in this area should target the income disparity in cancer screening and simultaneously explore how best to collect measures of poverty.

Keywords: Screening, Cervical cancer, Colorectal cancer, Breast cancer, Social determinants of health

\footnotetext{
*Correspondence: aisha.lofters@utoronto.ca

${ }^{1}$ Department of Family \& Community Medicine, St. Michael's Hospital, 30

Bond Street, Toronto, ON M5B 1W8, Canada

${ }^{2}$ Department of Family \& Community Medicine, University of Toronto, 500

University Avenue, 5th Floor, Toronto, ON M5G 1V7, Canada

Full list of author information is available at the end of the article
} 


\section{Background}

The social determinants of health $(\mathrm{SDOH})$, such as income, race/ethnicity, education, and working and living conditions, are responsible for substantial morbidity and mortality worldwide, with income being perhaps the most important determinant [1-8]. The World Health Organization defines the $\mathrm{SDOH}$ as "the conditions in which people are born, grow, work, live and age, and the wider set of forces and systems shaping the conditions of daily life" [9]. The SDOH influence one's healthrelated behaviours, health literacy levels, sense of selfcontrol and self-efficacy, and access to societal resources including access to healthcare $[8,10]$. The Institute of Medicine is moving to capture $\mathrm{SDOH}$ in electronic medical records, due to increased recognition that data on the $\mathrm{SDOH}$ can provide crucial information useful for treatment choices, health care system design and targeted innovations [11].

Quality primary care has been associated with an attenuation of the health effects of income inequalities $[12,13]$, making primary care a highly appropriate healthcare setting in which to measure and intervene on the $\mathrm{SDOH}$, especially with the expansion of multidisciplinary patient-centred teams $[14,15]$. However, individual-level data and practice-level data on the SDOH are rarely available within the primary care context and the best way to systematically collect and use these data in the primary care setting is not yet clear. Improving colorectal, cervical and breast cancer screening uptake for patients is an example of an area in primary care where data on the $\mathrm{SDOH}$ could be valuable, as disparities in cancer screening at the population level are well established, particularly related to income and foreign-born status [16-27].

In our large urban primary care practice in Ontario, Canada, we now routinely collect data on the $\mathrm{SDOH}$ from our patients using a self-completed survey in the waiting room. These data allow us to identify potential gaps in care related to SDOH and target our quality improvement efforts [28]. In this study, we aimed to understand: i) the relationship between the $\mathrm{SDOH}$, particularly income, and colorectal, cervical and breast cancer screening, and ii) challenges and opportunities of using $\mathrm{SDOH}$ data from a self-administered patient survey.

\section{Methods}

\section{Study setting}

Our study was conducted in a large Family Health Team, a common medical home model in Ontario, Canada [29]. Our Family Health Team is comprised of six clinics, approximately 70 physicians, and 60 other health professionals serving over 35,000 patients. Our practice is situated in downtown Toronto, Canada's most populous and sociodemographically diverse city with approximately 2.6 million people.
In the province of Ontario, cancer screening is covered through the universal provincial healthcare plan. Ontario has organized screening programs for colorectal, cervical and breast cancers, which include invitations, information about test results, and reminders for when it is time to repeat screening sent directly to residents of the province who are screen-eligible [30-32]. However, cancer screening is still fundamentally embedded in primary care.

\section{Collection of patient-level SDOH data}

Since 2014, our practice has been routinely collecting individual-level data from our patients through a voluntary sociodemographic survey (See Additional File 1), completed in the waiting room at routine office visits. Details on survey development are published elsewhere [28]. Briefly, the survey was developed by a multiorganizational steering committee, refined by an iterative process, and pilot tested with 400 patients.

The survey is completed either on an electronic tablet or on paper and then transferred to the electronic medical record (EMR) by clerical staff. For both methods, responses to the survey questions are stored directly in the patient's EMR and are immediately available for viewing. The survey is available in Canada's two official languages, English and French. Participants are able to select "prefer not to answer" or "do not know" for all questions, and no questions are mandatory. As of June 30 , 2015, approximately $30 \%$ of patients had participated in the survey. We used the survey to obtain individuallevel data on the $\mathrm{SDOH}$, specifically, immigrant status, ethnicity, household income and number of people in the household, sexual orientation, preferred language of communication, and housing status.

\section{Study participants}

We included all patients of the family practice who were eligible for at least one of the three cancer screening types, based on age and screening guidelines [33-35] as of June 30, 2015 and who had answered at least one question on the sociodemographic survey. Adults were eligible for colorectal cancer screening if they were 50 74 years of age, and women were eligible for cervical and breast cancer screening if they were $21-69$ years or $50-74$ years respectively. We obtained data on cancer screening eligibility from a monthly cancer screening report provided to Ontario family physicians by the provincial cancer agency. The monthly report provides information to physicians on which of their patients are eligible for and due for each of the three types of cancer screening based on provincial guidelines [36]. Screening data are obtained from diagnostic and fee codes billed throughout the province. On the monthly screening report, patients who have a personal history of one of the three cancers are excluded from eligibility for that 
particular screening modality, and men and women with a history of a colectomy are excluded from colorectal cancer screening. Women with a history of total hysterectomy are excluded from eligibility for cervical cancer screening, and those with a history of a mastectomy or enrolment in the Ontario Breast Screening Program's High Risk Screening Program are excluded from eligibility for breast cancer screening.

\section{Outcome definition}

We used data provided on the provincial cancer agency's monthly report to determine the screening status for patients eligible for colorectal and breast cancer screening. In our setting, most Pap tests were processed in a hospital laboratory and thus excluded from the provincial report, so to determine cervical cancer screening we combined data from the provincial agency with data from our practice's EMR. Study participants were categorized as being up-to-date for screening (binary variable: yes/no) for each of the three cancers of interest. Screening status was defined as of June 30, 2015. For the three outcome variables, up-to-date was defined as at least one documented faecal occult blood test in the last two years, flexible sigmoidoscopy in the last five years, or colonoscopy in the last ten years (colorectal cancer screening), at least one Pap test in the last three years (cervical cancer screening) and at least one mammogram in the last two years (breast cancer screening).

\section{Survey variables}

To identify individual-level income, we used responses from the sociodemographic survey to create an adapted version of the Low-Income Cutoff Before Taxes (LICOBT) used by Statistics Canada [37]. The LICO-BT is the income threshold below which an affected family would be expected to spend at least $20 \%$ more of its household income on necessities (food, shelter, clothing) than the average family [37]. Cut-offs vary by family size and by area of residence to reflect differences in cost of living. To create an adapted LICO-BT variable, we used the responses from two survey questions: i) What was your total family income before taxes last year? (where response categories were in $\$ 30,000$ increments), and ii) How many people does your income support? (see Additional file 1, questions 7 and 8). We correlated responses with the 2014 LICO-BT calculations for a Census Metropolitan Area of 500,000 inhabitants or more available from Statistics Canada. If participants reported a total family income before taxes of $\$ 0$ to $\$ 29,999$ and reported that their income supported two people or less they were considered below the LICO-BT. Similarly, if participants reported a total family income before taxes of $\$ 0$ to $\$ 29,999$ or $\$ 30,000$ to $\$ 59,999$ and reported their income supported between 3 to 6 people they were considered to be below the LICO-BT.
The survey includes a question on housing status with nine categories excluding "prefer not to answer" and "do not know" (see Additional file 1, question 11). We created a three-level variable for housing status (homeowners, renters, and other). Respondents in the "other" housing category reported that they lived in a boarding home, correctional facility, group home, shelter, hostel, supportive housing, on the street, or selected "other".

The sociodemographic survey includes one question on race/ethnicity that provides sixteen potential responses, excluding "prefer not to answer" and "do not know" (see Additional file 1, question 3). Potential responses included "First Nations", "Indigenous/Aboriginal" and "Metis", all of which refer to Canada's indigenous peoples. As the survey was not developed using Ownership, Control, Access and Possession principles, we chose to include data for these respondents with respondents who selected other. These principles enable self-determination over all research concerning Canada's indigenous peoples, and include "the right to make decisions about what, why, how and by whom information is collected, as well as how it will be used and shared" [38].

\section{Additional study variables}

Other variables collected from the EMR and monthly report included age, sex, and postal code. In addition to individual-level income, we determined neighbourhood income quintile. Patients' postal codes were categorized into neighbourhood income quintiles using the Statistics Canada Postal Code Conversion File and data from the 2006 Census (the last Census for which accurate data are available).

\section{Data analysis}

We used descriptive statistics to describe study participants for each variable of interest noted above, and used chi-squared tests to compare screening uptake, age, sex (for colorectal cancer screening only), and neighbourhood income quintile amongst study participants to the rest of the patient population eligible for screening for each cancer type. We compared the characteristics of patients who were overdue for screening to those who were up-to-date for screening for each cancer type using chi-squared tests. Age was characterized as both a continuous variable and a categorical variable using the following categories: 20-29 years, 30-39 years, 40-49 years, 50-59 years, 60-69 years, and 70 plus years. We compared the age of patients who were overdue for screening to those who were up-to-date for screening using both independent samples t-tests (continuous variable) and chi-squared tests (categorical variable). Participants with missing data or who had selected "prefer not to answer" or "do not know" were excluded from bivariate analyses. In bivariate analyses, ethnicity 
was collapsed to White versus all other ethnicities because of the small numbers in the latter category. A two-tailed test was used and a p-value of less than 0.05 was considered statistically significant. All statistical analyses were conducted using SPSS 20.0 [39].

\section{Results}

We analysed data for 5766 patients who answered at least one question on the sociodemographic survey (Fig. 1). Table 1 describes the sociodemographic characteristics of the study participants, including missing data, as well as the proportion of patients up-to-date on the three screening types by sociodemographic subgroup. These categories were not mutually exclusive; 1207 women were eligible for all three screening types. There was a large amount of missing data for the LICO-BT variable, approximately $25 \%$ across the three cohorts.

Patients who completed the sociodemographic survey were significantly more likely to be up-to-date on colorectal, cervical and breast cancer screening than those who did not complete the sociodemographic survey (Fig. 2). Study participants were most likely to be up-to-date on cervical cancer screening (78.7\%) and least likely for CRC screening $(72.9 \%)$, which also held true for the general practice population. No significant differences were observed for any of the screening modalities based on age or neighbourhood income quintile (data not shown) between participants who completed the sociodemographic survey and those who did not complete the sociodemographic survey. Among those eligible for colorectal cancer screening,

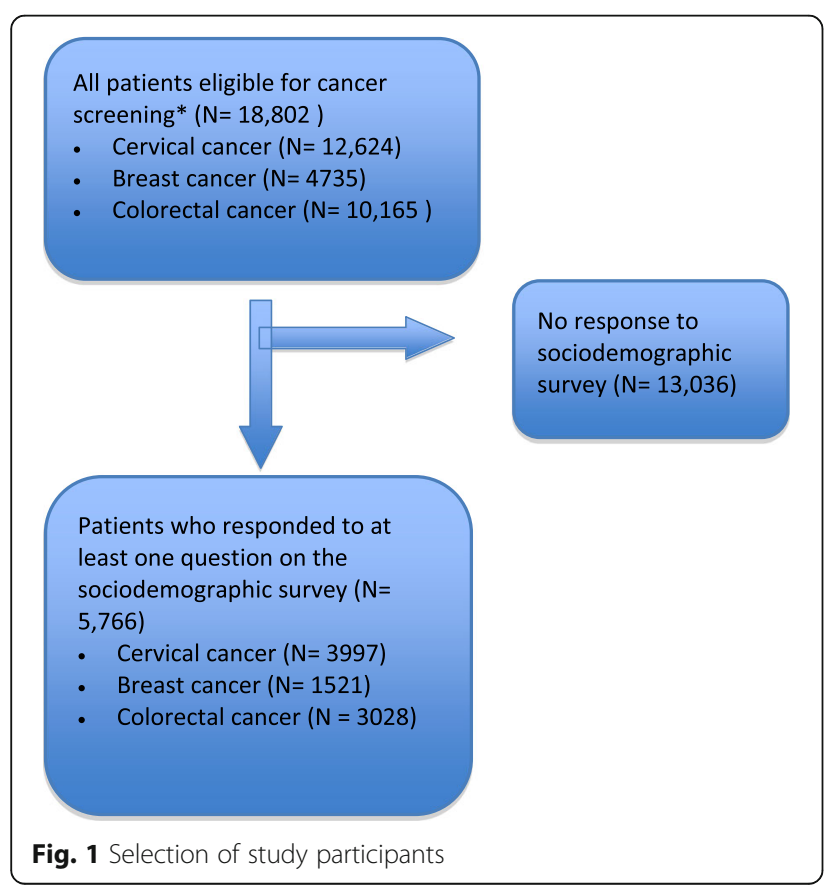

female patients were more likely to complete the sociodemographic survey than male patients.

In bivariate analyses (Table 2), age, immigrant status, income and housing showed statistically significant associations with cancer screening. Patients who were up-todate with colorectal cancer screening were significantly older than those were overdue, whereas those who were up-to-date with cervical cancer screening were significantly younger than those were overdue. Foreign-born patients were more likely to be up-to-date on colorectal screening than their Canadian-born peers but showed no significant differences in breast or cervical cancer screening. Although there were no significant differences for any of the screening modalities based on neighbourhood income quintile, the derived LICO-BT variable was associated with all three screening types. People living below the LICO-BT were less likely to be up-to-date on screening for all screening types and this difference was most marked for breast cancer screening. Housing status was also associated with all three cancer screening types. Screening was less common among patients who rented a home and those who reported their housing as "other" than among those who owned a home. There were differences in breast and cervical cancer screening between heterosexual and non-heterosexual women but these were not statistically significant.

We did not conduct multivariable analyses because of the large amount of missing data for income (approximately $25 \%$ ), which was our main variable of interest. It was not possible to use neighbourhood income as a proxy in multivariable analysis because there was not a high level of agreement between neighbourhood income and the LICO. For example, $50.9 \%$ of participants in the lowest income quintile and $65.5 \%$ of participants in the second lowest income quintile lived above the LICO.

To better understand our results, we looked at the relationship between housing status and LICO-BT status. Of those who were homeowners, the vast majority lived above the LICO-BT $(90.1 \%$ for the CRC screening cohort, $90.9 \%$ for cervical cohort, $89.4 \%$ for breast cohort). Similarly, of those who lived in "other" housing i.e. were neither homeowners nor renters, most were below the LICO-BT (81.1\% for CRC cohort, $76.2 \%$ for cervical cohort, $76.6 \%$ for breast cohort).

\section{Discussion}

We used self-reported SDOH data within the primary care setting to describe the association between the SDOH and clinical outcomes: colorectal, cervical and breast cancer screening. We found that participants living below a lowincome threshold indicative of poverty and people who did not own their homes were significantly less likely to be screened for cancers than their more advantaged peers. However, we also found that patients who responded to 
Table 1 Subset of patients with survey data available ${ }^{a}$

\begin{tabular}{|c|c|c|c|c|c|c|}
\hline & \multicolumn{2}{|c|}{ Colorectal cancer } & \multicolumn{2}{|c|}{ Cervical cancer } & \multicolumn{2}{|l|}{ Breast cancer } \\
\hline & $\begin{array}{l}\text { Eligible for } \\
\text { screening, } N\end{array}$ & $\begin{array}{l}\text { Receiving } \\
\text { Screening, } \\
\text { row \% }\end{array}$ & $\begin{array}{l}\text { Eligible for } \\
\text { screening, N }\end{array}$ & $\begin{array}{l}\text { Receiving } \\
\text { Screening, } \\
\text { row \% }\end{array}$ & $\begin{array}{l}\text { Eligible for } \\
\text { screening, N }\end{array}$ & $\begin{array}{l}\text { Receiving } \\
\text { Screening, } \\
\text { row \% }\end{array}$ \\
\hline TOTAL & 3028 & 72.9 & 3997 & 78.7 & 1521 & 74.4 \\
\hline \multicolumn{7}{|l|}{ Age categories } \\
\hline $20-29$ & -- & -- & 618 & 76.7 & -- & -- \\
\hline $30-39$ & -- & -- & 1149 & 81.4 & -- & -- \\
\hline $40-49$ & -- & -- & 960 & 82.9 & -- & -- \\
\hline $50-59$ & 1588 & 67.3 & 760 & 77.9 & 797 & 72.8 \\
\hline $60-69$ & 1091 & 78.5 & 510 & 68.0 & 540 & 77.4 \\
\hline $70+$ years & 349 & 81.1 & -- & -- & 184 & 72.8 \\
\hline \multicolumn{7}{|l|}{ Sex } \\
\hline Male & 1433 & 72.6 & -- & -- & -- & -- \\
\hline Female & 1595 & 73.2 & 3997 & 78.7 & 1521 & 74.4 \\
\hline \multicolumn{7}{|l|}{ Immigrant status } \\
\hline Foreign-born & 1203 & 75.8 & 1604 & 77.7 & 654 & 76.0 \\
\hline Canadian-born & 1722 & 71.4 & 2317 & 79.5 & 817 & 73.6 \\
\hline Prefer not to answer/Do not know/Missing & 103 & 64.1 & 76 & 73.7 & 50 & 68.0 \\
\hline \multicolumn{7}{|l|}{ Ethnicity } \\
\hline White-North American & 1173 & 73.1 & 1325 & 80.1 & 564 & 74.3 \\
\hline White-European & 724 & 73.5 & 773 & 78.1 & 334 & 73.4 \\
\hline Asian - East (e.g., Chinese, Japanese, Korean) & 144 & 79.2 & 255 & 81.6 & 82 & 82.9 \\
\hline Asian - South East (e.g., Malaysian, Filipino, Vietnamese) & 126 & 73.0 & 203 & 77.8 & 92 & 84.8 \\
\hline Asian - South (e.g., Indian, Pakistani, Sri Lankan) & 124 & 74.2 & 299 & 76.6 & 64 & 78.1 \\
\hline Black - African (e.g., Ghanaian, Kenyan, Somali) & 73 & 80.8 & 204 & 78.9 & 47 & 70.2 \\
\hline Black - Caribbean (e.g., Barbadian, Jamaican) & 87 & 75.9 & 169 & 77.5 & 59 & 72.9 \\
\hline Black - North American (e.g., Canadian, American) & 17 & 64.7 & 29 & 72.4 & 8 & 75.0 \\
\hline Indian - Caribbean (e.g., Guyanese with origins in India) & 40 & 57.5 & 43 & 81.4 & 24 & 70.8 \\
\hline Latin American (e.g., Argentinean, Chilean, Salvadorian) & 86 & 73.3 & 129 & 76.7 & 35 & 80.0 \\
\hline Middle Eastern (e.g., Egyptian, Iranian, Lebanese) & 40 & 70.0 & 67 & 68.7 & 13 & 84.6 \\
\hline Mixed heritage (e.g., Black- African and White-North American & 25 & 64.0 & 93 & 76.3 & 11 & 72.7 \\
\hline $\begin{array}{l}\text { Other (including First Nations/Indigenous/Aboriginal not included } \\
\text { elsewhere/Inuit/Métis) }\end{array}$ & 113 & 69.0 & 154 & 84.4 & 55 & 56.4 \\
\hline Prefer not to answer/Do not know/Missing & 256 & 68.8 & 254 & 74.8 & 133 & 71.4 \\
\hline \multicolumn{7}{|l|}{ Neighbourhood income quintile } \\
\hline Q1 & 714 & 73.2 & 949 & 76.4 & 337 & 70.0 \\
\hline Q2 & 447 & 72.9 & 633 & 79.5 & 230 & 73.0 \\
\hline Q3 & 451 & 71.8 & 612 & 78.1 & 251 & 74.1 \\
\hline Q4 & 477 & 73.2 & 600 & 79.0 & 261 & 75.9 \\
\hline Q5 & 738 & 75.5 & 826 & 82.1 & 353 & 77.6 \\
\hline Missing & 201 & 63.7 & 377 & 75.9 & 89 & 78.7 \\
\hline \multicolumn{7}{|l|}{ Low-income cut-off, before taxes (LICO-BT) $)^{\mathrm{b}}$} \\
\hline Below low-income cut-off & 710 & 68.6 & 836 & 76.4 & 312 & 64.7 \\
\hline Above low-income cut-off & 1529 & 74.9 & 2130 & 80.9 & 769 & 79.8 \\
\hline Prefer not to answer/Do not know/Missing & 789 & 72.9 & 1031 & 75.6 & 440 & 71.8 \\
\hline
\end{tabular}




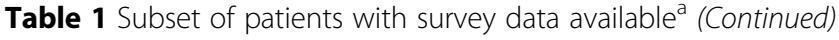

\begin{tabular}{|c|c|c|c|c|c|c|}
\hline \multicolumn{7}{|l|}{ Sexual orientation } \\
\hline Heterosexual & 2305 & 72.8 & 3395 & 79.3 & 1300 & 74.6 \\
\hline Gay/Bisexual/Lesbian/Queer/Two-Spirit/Other & 463 & 72.4 & 277 & 75.1 & 71 & 66.2 \\
\hline Prefer not to answer/Do not know/Missing & 260 & 74.6 & 325 & 75.1 & 150 & 76.7 \\
\hline \multicolumn{7}{|l|}{ Language } \\
\hline \multicolumn{7}{|c|}{ What language would you feel most comfortable speaking in with your healthcare provider? } \\
\hline English & 2875 & 72.9 & 3732 & 78.6 & 1437 & 74.4 \\
\hline Other Language & 136 & 72.1 & 252 & 79.4 & 77 & 77.9 \\
\hline Prefer not to answer/Do not know/Missing & 17 & 76.5 & 13 & 76.9 & 7 & 42.9 \\
\hline \multicolumn{7}{|c|}{ In what language would you prefer to read healthcare information? } \\
\hline English & 2750 & 73.1 & 3656 & 78.7 & 1379 & 74.3 \\
\hline Other language & 115 & 67.8 & 211 & 79.1 & 61 & 73.8 \\
\hline Prefer not to answer/Do not know/Missing & 163 & 72.4 & 130 & 76.9 & 81 & 77.8 \\
\hline \multicolumn{7}{|l|}{ Housing } \\
\hline Own Home & 1508 & 75.5 & 1744 & 81.9 & 805 & 79.0 \\
\hline Renting Home & 942 & 71.3 & 1697 & 76.6 & 442 & 73.8 \\
\hline Other & 325 & 65.5 & 284 & 74.3 & 147 & 59.2 \\
\hline Prefer not to answer/Do not know/Missing & 253 & 72.3 & 272 & 75.0 & 127 & 65.4 \\
\hline
\end{tabular}

${ }^{\mathrm{S}} \mathrm{Screening}$ rates are reported as row percentages

b LICO-BT derived from 2014 Statistics Canada LICO-BT calculations with the following modifications:

i) if participants reported a total family income before taxes of $\$ 0$ to $\$ 29,999$ (question \#7) and reported that their income supported $\leq 2$ people (question \#8) they were below the LICO-BT

ii) if participants reported a total family income before taxes of $\$ 0$ to $\$ 29,999$ or $\$ 30,000$ to $\$ 59,999$ (question \#7) and reported their income supported between 3 to 6 people (question \#8) they were below the LICO-BT

iii) if participants reported a total family income before taxes of $\$ 0$ to $\$ 29,999$ or $\$ 30,000$ to $\$ 59,999$ or $\$ 60,000$ to $\$ 89,999$ (question \#7) and reported their income supported seven or more people (question \#8) they were below the LICO-BT

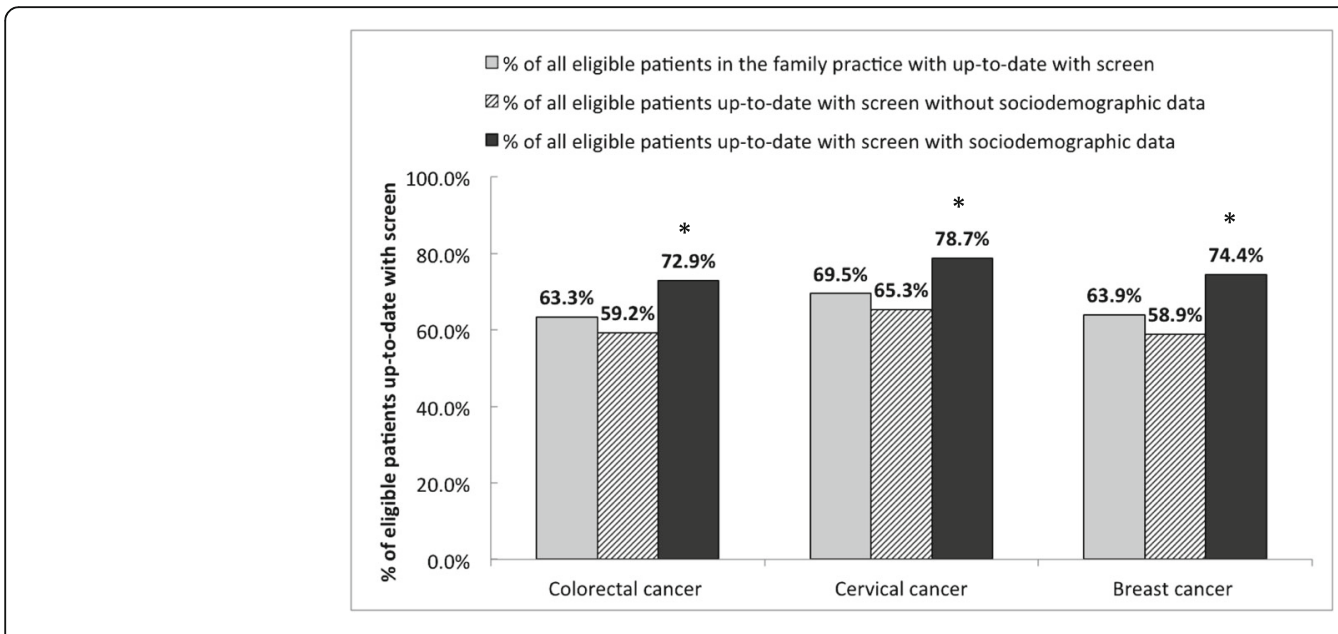

${ }^{*} \mathrm{p}$-value $<0.0001$ for the comparison of screening uptake among patients with vs. without sociodemographic data for all thre screening types from Pearson's chi-squared test.

Fig. 2 Colorectal, cervical, and breast cancer screening rates for all eligible patients and eligible patients with survey data. ${ }^{*} p$-value $<0.0001$ for the comparison of screening uptake among patients with vs. without sociodemographic data for all three screening types from Pearson's chi-squared test 
Table 2 Bivariate results for screening rates among patients with survey data ${ }^{a}$

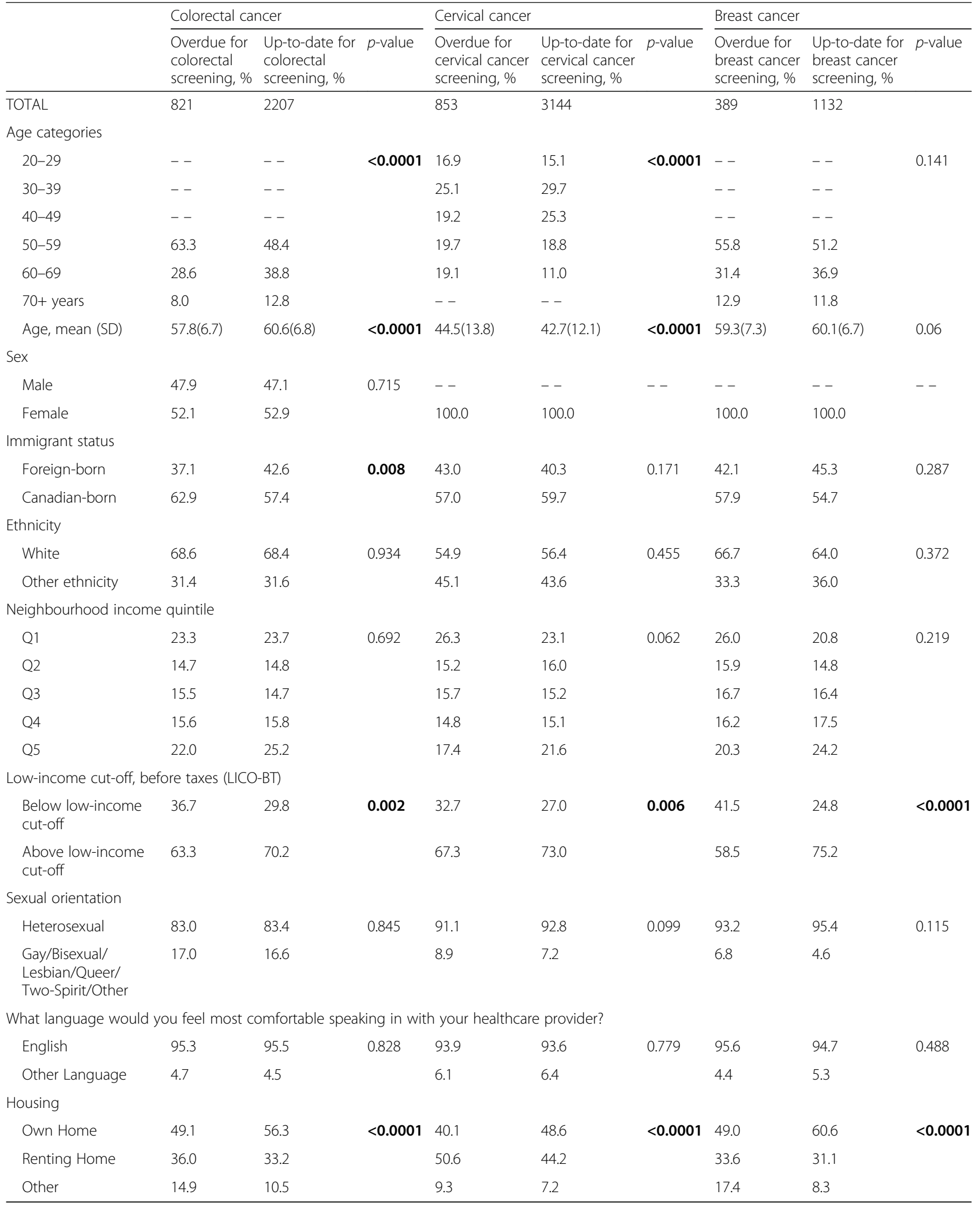

${ }^{\mathrm{a} S c r e e n i n g}$ rates reported as column percentages

Statistically significant $p$-values were bolded 
the sociodemographic survey were not typical of all patients in the practice, with higher cancer screening rates than patients who did not respond to the survey. Although we were able to use survey data to formulate a low-income cut-off based on the Statistics Canada definition, there was a large amount of missing income information, approximately $25 \%$ across the three cancer screening cohorts, precluding us from conducting multivariable analyses. It is possible that income was on the causal pathway of the relationship we observed between housing status and screening. Other variables (e.g. age) may have also confounded the relationships we observed between income and screening and housing and screening or acted as intermediate factors.

Our study highlights opportunities in the use of selfreported SDOH data in primary care. We found a significant association between the low-income cut-off variable and cancer screening despite the high amount of missing income data, and despite neighbourhood income quintile not being associated with cancer screening. Most studies on income inequities in health use neighbourhood income as a proxy for individual income, as the latter is often not available [19, 23, 25, 27, 40-44]. Our results demonstrate that neighbourhood income may under-represent income-related inequalities and were not in high agreement with the individual-level LICO. This may be especially true in urban centres like Toronto where the demographics of neighbourhoods are changing rapidly and faster than a quinquennial census can accurately track [45].

We also found intriguing results based on housing status. We found no other studies that examined the relationship between housing status and cancer screening. However, housing status has been associated with other aspects of cancer care in the international literature. A recent U.S. study showed that both renters and people in unstable housing had delays in the time to diagnostic resolution after a cancer screening abnormality when compared to homeowners, potentially due to barriers such as coordination and scheduling, transportation, childcare and low literacy [46]. Hagedoorn et al. found that home ownership (versus tenancy) provided a beneficial effect on lung cancer mortality in Belgium [47]. Housing status may simply be a marker of income, but it may also be a marker of wealth or social stability. Future research should further explore the causal pathway that lies between housing and cancer screening, taking into account sociodemographic variables that have been previously found to be associated with cancer screening, such as age, income, immigrant status, and co-morbidities, and that could serve as confounders for observed associations [19, 23, 26, 27, 48, 49].

Our results also highlight several challenges in collecting individual-level income status using self-reported data. One-quarter of participating patients did not provide a household income; missing data for other social determinants were otherwise less than $10 \%$. Our findings of missing income are in line with previous literature. Kirst et al. found that $67 \%$ of Ontario residents were uncomfortable with disclosing household income and there was a general lack of awareness of the importance of collecting sociodemographic data [50]. Similarly, a national survey conducted in 2009 found that $65 \%$ of Canadian respondents were uncomfortable with the collection of household income in healthcare settings [51]. Respondents were most comfortable with sociodemographic data being directly collected by their family physician and certain groups were more comfortable with the collection of income, such as visible minorities and males [51].

It is possible that asking about socioeconomic status in different ways might have been more acceptable to our survey participants and might have led to less missing data. The question "Do you have difficulty making ends meet at the end of the month?" has been found to be a good predictor in a Canadian primary care population of being below the low-income cut-off, with a sensitivity of $98 \%$ and specificity of $40 \%$, with the caveat that non-English speakers may not understand this colloquial term [52]. Future research could test such questions for their acceptability and validity in our setting [15]. Interestingly, in the pilot testing of our sociodemographic survey, only $10.1 \%$ of patients did not answer the income question [28], stressing the importance of ongoing postimplementation surveillance of such initiatives.

We also experienced several other challenges with collecting and using SDOH data. First, although there were a large number of categories for ethnicity in the survey, many of these categories had quite small cell sizes. We also had data on indigenous persons that we did not feel comfortable using due to a lack of adherence to Ownership, Control, Access and Possession principles [38]. We ultimately collapsed these categories into White vs. nonWhite for bivariate analyses. However, different categorizations might have led to more meaningful ethnicitybased screening results. How to best categorize ethnicity while maximizing both sample size and granularity needs to be further explored. Second, our survey was only available in English or French, which may explain the low proportion of patients in our survey who reported their preferred language as one other than English. This may have dissuaded some foreign-born patients from participating in the survey, and may partially explain why we saw no disparities based on immigrant status. Third, study participants were not representative of all patients in the practice, as noted by their higher screening rates. Participants were all willing to answer a waiting room survey, so it is plausible that they may have been more likely to come in for visits than other patients and that they may also have been more likely to be intrinsically motivated to 
participate in prevention and screening manoeuvres. These latter two points may partially explain why we found no disparities in screening for foreign-born patients despite well-documented disparities at the provincial level [23, 26, 44]. Fourth, although a sizeable proportion of our patients have completed the survey, detecting differences in care among some patient groups (e.g. non-heterosexual patients, certain ethnic groups) would likely require a larger sample. Fifth, the survey did not include a question on education, another known social determinant of health. Prior research demonstrates that higher education levels are positively associated with colorectal, cervical cancer, and breast cancer screening adherence [53-55]. Sixth, we were unable to track family history of cancer, which has been shown to be a motivator for cancer screening [56-59]. Seventh, younger participants in our study had less opportunity for cancer screening, which may at least partially explain our findings on age and colorectal cancer screening. Finally, it is plausible that the missing data encountered in all questions was non-random and potentially biased our findings.

\section{Conclusions}

Our experiences highlight key considerations for primary care providers and researchers interested in collecting and intervening on $\mathrm{SDOH}$ in primary care. While we were able to show that neighbourhood income might under-estimate income-related disparities in screening, individual-level income was also the most challenging variable to collect. Future work in this area should focus on targeted interventions that reduce income-related disparities in cancer screening [60] and simultaneously continue to explore how best to collect socioeconomic data, particularly measures of poverty. Further research is also needed to understand whether housing is an independent risk factor for under-screening.

\section{Additional file}

Additional file 1: Sociodemographic survey. Sociodemographic survey completed in the waiting room at routine office visits. (PDF $220 \mathrm{~kb}$ )

\section{Abbreviations \\ EMR: Electronic medical record; LICO-BT: Low-Income Cutoff Before Taxes; SDOH: Social determinants of health}

\section{Acknowledgements}

The authors thank Ms. Lisa Miller for her technical assistance.

\section{Funding}

This study was supported by a research grant from the St. Michael's Foundation Translational Innovation Fund. Dr. Lofters. Dr. Pinto, Dr. Persaud and Dr. Kiran are supported as Clinician Scientists by the University of Toronto Department of Family \& Community Medicine. Dr. Lofters is supported by a Canadian Cancer Society Research Institute Career Development Award in Cancer Prevention. Dr. Kiran is supported by a Canadian Institutes of Health Research
Embedded Clinician Researcher Award. Dr. Persaud is funded by a PSI Graham Farquharson Knowledge Translation Fellowship. The funders had no role in study design, data collection and analysis, decision to publish, or preparation of the manuscript.

\section{Availability of data and materials}

The data supporting the conclusions of this article are not available in a public repository, but can be available upon request to the corresponding author (AKL), in accordance with St. Michael's Hospital Research Ethics Board policies.

\section{Authors' contributions}

AL and TK conceived of the study; AL, TK, and MS participated in the design of the study; AS analyzed the quantitative data; AL drafted the manuscript; TK, AS, MS, NB, NP, AP, EK, SK, and RN participated in the preparation of the manuscript by providing critical revisions of drafts; and all authors read and approved the final manuscript.

\section{Competing interests}

The authors declare that they have no competing interests.

\section{Consent for publication}

Not applicable.

\section{Ethics approval and consent to participate}

This study received ethics approval from the St. Michael's Hospital Research Ethics Board. The need for consent to participate was waived by the St. Michael's Hospital Research Ethics Board as the research study satisfies all the conditions for secondary use of identifiable information for research purposes in Article 5.5A (a) to (f) of the Tri-Council Policy Statement on Ethical Conduct for Research Involving Humans.

\section{Author details}

'Department of Family \& Community Medicine, St. Michael's Hospital, 30 Bond Street, Toronto, ON M5B 1W8, Canada. ${ }^{2}$ Department of Family \& Community Medicine, University of Toronto, 500 University Avenue, 5th Floor, Toronto, ON M5G 1V7, Canada. ${ }^{3}$ Centre for Urban Health Solutions, Li Ka Shing Knowledge Institute, St. Michael's Hospital, 30 Bond Street, Toronto, ON M5B 1W8, Canada. ${ }^{4}$ Dalla Lana School of Public Health, University of Toronto, Health Sciences Building, 155 College Street, 6th Floor, Toronto, ON M5T 3M7, Canada. ${ }^{5}$ Department of Surgery, Li Ka Shing Knowledge Institute, St. Michael's Hospital, 30 Bond Street, Toronto, ON M5B 1W8, Canada.

${ }^{6}$ Cancer Care Ontario, 620 University Avenue, Toronto, ON M5G 2L7, Canada. ${ }^{7}$ Institute for Clinical Evaluative Sciences, 2075 Bayview Avenue, Toronto, Ontario M4N 3M5, Canada.

Received: 6 September 2016 Accepted: 9 February 2017

Published online: 28 February 2017

References

1. Determinants of Health: What Makes Canadians Healthy or Unhealthy? http://www.phac-aspc.gc.ca/ph-sp/determinants/determinants-eng. php\#unhealthy. Accessed 17 Feb 2017.

2. Chandola T, Ferrie J, Sacker A, Marmot M. Social inequalities in self reported health in early old age: follow-up of prospective cohort study. BMJ. 2007;334(7601):990.

3. Commission on Social Determinants of Health. Closing the gap in a generation: health equity through action on the social determinants of health. In: Final report of the commission on social determinants of health. Geneva: World Health Organization; 2008.

4. Galobardes B, Davey Smith G, Jeffreys M, McCarron P. Childhood socioeconomic circumstances predict specific causes of death in adulthood: the Glasgow student cohort study. J Epidemiol Community Health. 2006;60(6):527-9.

5. Lofters A, Slater M, Kirst M, Shankardass K, Quinonez C. How do people attribute income-related inequalities in health? a cross-sectional study in Ontario, Canada. PLoS One. 2014;9(1):e85286

6. Marmot M. Social determinants of health inequalities. Lancet. 2005; 365(9464):1099-104.

7. Marmot M, Friel S. Global health equity: evidence for action on the social determinants of health. J Epidemiol Community Health. 2008:62(12):1095-7.

8. Mikkonen J, Raphael D. Social determinants of health: the Canadian facts. Toronto: York University School of Health Policy and Management; 2010. 
9. Social determinants of health. http://www.who.int/social_determinants/en/. Accessed 17 Feb 2017.

10. Bierman AS, Magari ES, Jette AM, Splaine M, Wasson JH. Assessing access as a first step toward improving the quality of care for very old adults. J Ambul Care Manage. 1998;21(3):17-26.

11. Institute of Medicine. Capturing social and behavioral domains in electronic health records: phase 1. Washington: National Academies Press; 2014.

12. Shi L, Starfield B. The effect of primary care physician supply and income inequality on mortality among blacks and whites in US metropolitan areas. Am J Public Health. 2001;91 (8):1246-50.

13. Starfield B, Shi L, Macinko J. Contribution of primary care to health systems and health. Milbank Q. 2005;83(3):457-502.

14. DeVoe JE, Bazemore AW, Cottrell EK, Likumahuwa-Ackman S, Grandmont J, Spach N, Gold R. Perspectives in primary care: a conceptual framework and path for integrating social determinants of health into primary care practice. Ann Fam Med. 2016;14(2):104-8.

15. Gottlieb LM, Tirozzi KJ, Manchanda R, Burns AR, Sandel MT. Moving electronic medical records upstream: incorporating social determinants of health. Am J Prev Med. 2015;48(2):215-8.

16. Borkhoff CM, Saskin R, Rabeneck L, Baxter NN, Liu Y, Tinmouth J, Paszat LF Disparities in receipt of screening tests for cancer, diabetes and high cholesterol in Ontario, Canada: a population-based study using area-based methods. Can J Public Health. 2013;104(4):e284-290.

17. Fernandes KA, Sutradhar R, Borkhoff CM, Baxter N, Lofters A, Rabeneck L, Tinmouth J, Paszat L, Ontario Cancer Screening Research N. Small-area variation in screening for cancer, glucose and cholesterol in Ontario: a cross-sectional study. CMAJ Open. 2015;3(4):E373-81.

18. Glazier RH, Creatore MI, Gozdyra P, Matheson FI, Steele LS, Boyle E, Moineddin R. Geographic methods for understanding and responding to disparities in mammography use in Toronto, Canada. J Gen Intern Med. 2004;19(9):952-61.

19. Guilcher SJ, Lofters A, Glazier RH, Jaglal SB, Voth J, Bayoumi AM. Level of disability, multi-morbidity and breast cancer screening: does severity matter? Prev Med. 2014;67:193-8.

20. Honein-AbouHaidar GN, Baxter NN, Moineddin R, Urbach DR, Rabeneck L, Bierman AS. Trends and inequities in colorectal cancer screening participation in Ontario, Canada, 2005-2011. Cancer Epidemiol. 2013;37(6):946-56.

21. Kiran T, Wilton AS, Moineddin R, Paszat L, Glazier RH. Effect of payment incentives on cancer screening in Ontario primary care. Ann Fam Med. 2014;12(4):317-23

22. Lofters A, Guilcher S, Maulkhan N, Milligan J, Lee J. Patients living with disabilities: the need for high-quality primary care. Can Fam Physician. 2016;62(8):e457-464.

23. Lofters AK, Hwang SW, Moineddin R, Glazier RH. Cervical cancer screening among urban immigrants by region of origin: a population-based cohort study. Prev Med. 2010;51(6):509-16.

24. Lofters AK, Moineddin R, Hwang SW, Glazier RH. Low rates of cervical cancer screening among urban immigrants: a population-based study in Ontario, Canada. Med Care. 2010;48(7):611-8.

25. Lofters AK, Moineddin R, Hwang SW, Glazier RH. Predictors of low cervical cancer screening among immigrant women in Ontario, Canada. BMC Womens Health. 2011:11:20.

26. Lofters A, Ng R, Lobb R. Primary care physician characteristics associated with cancer screening: A retrospective cohort study in Ontario, Canada. Cancer Med. 2014. doi:10.1002/cam4.358.

27. Vahabi M, Lofters A, Kumar M, Glazier RH. Breast cancer screening disparities among urban immigrants: a population-based study in Ontario, Canada. BMC Public Health. 2015;15:679.

28. Pinto AD, Glattstein-Young G, Mohamed A, Bloch G, Leung FH, Glazier RH. Building a foundation to reduce health inequities: routine collection of sociodemographic data in primary care. J Am Board Fam Med. 2016;29(3):348-55.

29. Rosser WW, Colwill JM, Kasperski J, Wilson L. Patient-centered medical homes in Ontario. N Engl J Med. 2010;362(3):e7.

30. About the Ontario Breast Screening Program. https://www.cancercare.on.ca/ pcs/screening/breastscreening/. Accessed 17 Feb 2017.

31. Cervical Screening - CCO. http://www.cancercare.on.ca/pcs/screening/ cervscreening/. Accessed 17 Feb 2017.

32. Ontario Cancer Plan 2008-2011. http://ocp.cancercare.on.ca/cms/One. aspx?portalid=14464\%pageid=14471. Accessed 17 Feb 2017.

33. Screening Guidelines - CCO. https:/www.cancercare.on.ca/pcs/screening/ breastscreening/breasthealth/. Accessed 17 Feb 2017.
34. Screening Guidelines - CCO. https://www.cancercare.on.ca/pcs/screening/ cervscreening/screening_guidelines/. Accessed 17 Feb 2017.

35. Screening. http://www.cancercare.on.ca/pcs/screening/. Accessed 17 Feb 2017.

36. Screening Activity Report. http://www.cancercare.on.ca/pcs/primcare/sar/. Accessed 17 Feb 2017.

37. Low Income Cut-Offs. http://www.statcan.gc.ca/pub/75f0002m/2012002/ lico-sfr-eng.htm. Accessed 17 Feb 2017.

38. First Nations Centre. OCAP: ownership, control, access and possession. In: Sanctioned by the first nations information governance committee, assembly of first nations. Ottawa: National Aboriginal Health Organization; 2007.

39. IBM Corp. IBM SPSS statistics for windows, version 20.0. Armonk: IBM Corp; 2011. Released.

40. Decker KM, Demers AA, Nugent Z, Biswanger N, Singh H. Reducing incomerelated inequities in colorectal cancer screening: lessons learned from a retrospective analysis of organised programme and non-programme screening delivery in Winnipeg, Manitoba. BMJ Open. 2016;6(2):e009470.

41. Elit L, Krzyzanowska M, Saskin R, Barbera L, Razzaq A, Lofters A, Yeritsyan N, Bierman A. Sociodemographic factors associated with cervical cancer screening and follow-up of abnormal results. Can Fam Physician. 2012;58(1):e22-31.

42. Kiran T, Kopp A, Moineddin R, Victor JC, Campbell RJ, Shah BR, Glazier RH. Unintended consequences of delisting routine eye exams on retinopathy screening for people with diabetes in Ontario, Canada. CMAJ. 2013; 185(3):E167-173.

43. Sholzberg M, Gomes T, Juurlink DN, Yao Z, Mamdani MM, Laupacis A. The influence of socioeconomic status on selection of anticoagulation for atrial fibrillation. PLoS One. 2016;11(2):e0149142.

44. Vahabi M, Lofters A, Kumar M, Glazier RH. Breast cancer screening disparities among immigrant women by world region of origin: a population-based study in Ontario, Canada. Cancer Med. 2016;5(7):1670-86.

45. Toronto Community Health Profiles. http://www.torontohealthprofiles.ca/. Accessed 17 Feb 2017

46. Rodday AM, Parsons SK, Snyder F, Simon MA, Llanos AA, Warren-Mears V, Dudley D, Lee JH, Patierno SR, Markossian TW, et al. Impact of patient navigation in eliminating economic disparities in cancer care. Cancer. 2015;121(22):4025-34.

47. Hagedoorn P, Vandenheede H, Willaert D, Vanthomme K, Gadeyne S. Regional inequalities in lung cancer mortality in Belgium at the beginning of the 21st century: the contribution of individual and area-level socioeconomic status and industrial exposure. PLoS One. 2016;11(1):e0147099.

48. Tilbrook D, Polsky J, Lofters A. Are women with psychosis receiving adequate cervical cancer screening? Can Fam Physician. 2010;56(4):358-63.

49. Lofters A, Guilcher S, Glazier R, Jaglal S, Voth J, Bayoumi A. Screening for cervical cancer in women with disability and multimorbidity: A retrospective cohort study in Ontario, Canada. CMAJ Open. 2014;2(4):E240-7. doi:10.9778/ cmajo.20140003.

50. Kirst M, Shankardass K, Bomze S, Lofters A, Quinonez C. Sociodemographic data collection for health equity measurement: a mixed methods study examining public opinions. Int J Equity Health. 2013;12(1):75.

51. Lofters AK, Shankardass K, Kirst M, Quinonez C. Sociodemographic data collection in healthcare settings: an examination of public opinions. Med Care. 2011:49(2):193-9.

52. Brcic V, Eberdt C, Kaczorowski J. Development of a tool to identify poverty in a family practice setting: a pilot study. Int J Family Med. 2011;2011:812182.

53. Limmer K, LoBiondo-Wood G, Dains J. Predictors of cervical cancer screening adherence in the United States: a systematic review. J Adv Pract Oncol. 2014;5(1):31-41.

54. Wools A, Dapper EA, de Leeuw JR. Colorectal cancer screening participation: a systematic review. Eur J Public Health. 2016;26(1):158-68.

55. Schueler KM, Chu PW, Smith-Bindman R. Factors associated with mammography utilization: a systematic quantitative review of the literature. J Womens Health (Larchmt). 2008;17(9):1477-98.

56. Bellinger JD, Brandt HM, Hardin JW, Bynum SA, Sharpe PA, Jackson D. The role of family history of cancer on cervical cancer screening behavior in a population-based survey of women in the Southeastern United States. Womens Health Issues. 2013;23(4)::197-204.

57. Laiyemo AO, Thompson N, Williams CD, Idowu KA, Bull-Henry K, Sherif ZA Lee EL, Brim H, Ashktorab H, Platz EA, et al. Race and colorectal cancer screening compliance among persons with a family history of cancer. World J Gastrointest Endosc. 2015;7(18):1300-5. 
58. Williams KP, Reiter P, Mabiso A, Maurer J, Paskett E. Family history of cancer predicts papanicolaou screening behavior for African american and white women. Cancer. 2009;115(1):179-89.

59. Ramsey SD, Yoon P, Moonesinghe R, Khoury MJ. Population-based study of the prevalence of family history of cancer: implications for cancer screening and prevention. Genet Med. 2006:8(9):571-5.

60. Berkowitz SA, Percac-Lima S, Ashburner JM, Chang Y, Zai AH, He W, Grant RW, Atlas SJ. Building equity improvement into quality improvement: reducing socioeconomic disparities in colorectal cancer screening as part of population health management. J Gen Intern Med. 2015;30(7):942-9.

Submit your next manuscript to BioMed Central and we will help you at every step:

- We accept pre-submission inquiries

- Our selector tool helps you to find the most relevant journal

- We provide round the clock customer support

- Convenient online submission

- Thorough peer review

- Inclusion in PubMed and all major indexing services

- Maximum visibility for your research

Submit your manuscript at www.biomedcentral.com/submit 